\title{
UM BREVE HISTÓRICO A RESPEITO DO ENSINO DA PSICOLOGIA NO ENSINO MÉDIO
}

\section{Leny Magalhães Mrech}

\section{RESUMO}

Este artigo disserta a respeito de alguns elementos da história do ensino de Psicologia no Brasil. Discute também os principais problemas e impasses trazidos pela implantação do Ensino de Psicologia na licenciatura em Psicologia e no ensino de Psicologia no ensino médio. Analisa, por último, alguns dos principais efeitos das Políticas Públicas em Licenciatura em Psicologia e em Psicologia no Ensino Médio.

\section{PALAVRAS-CHAVE}

História do ensino de psicologia no Brasil; O ensino de psicologia na licenciatura e no ensino médio; Políticas públicas na licenciatura em psicologia e na disciplina psicologia no ensino médio

\section{A SHORT BACKGROUND TO THE TEACHING OF PSYCHOLOGY IN HIGH SCHOOL}

\begin{abstract}
This article dissertates about some elements of the history of teaching of Psychology in Brazil. It also discusses the main problems and difficulties brought by the implementation of the teaching of psychology in teacher degree school, and of the teaching of psychology in high school.Finally, it analyses some of the main effects of the public policies in graduation in Psychology and in Psychology in High School.
\end{abstract}

\section{KEYWORDS}

History of teaching psychology in Brazil; The teaching of psychology teacher degree courses and high school; Public policies in graduation in psychology and on psychology subject in high school 


\section{DOSSIÊ \\ Área Temática: Ensino de Psicologia "Diálogos sobre a Docência em Psicologia"}

Apresentarei a seguir um breve histórico a respeito do ensino da Psicologia no Ensino Médio. Destacando que ele se iniciou cedo. E que, é bom destacar, sempre houve uma interação bastante próxima entre a Educação e a Psicologia em nosso país.

Para o estabelecimento de um olhar mais abrangente a respeito desta interação resolvemos dividir a história do ensino de Psicologia no Brasil em quatro grandes períodos:

1) Primódios da implantação das idéias psicológicas no país.

2) A Psicologia e o século XIX

3) A Psicologia e a primeira metade do século $X X$

4) A Psicologia e a segunda metade do século $X X$ : as bases para um novo milênio

\section{PRIMÓRDIOS DA IMPLANTAÇÃO DAS IDÉIAS PSICOLÓGICAS NO PAÍS}

Ao longo da história da humanidade a Educação e a Psicologia sempre tiveram uma relação privilegiada. A Educação ao cuidar da aprendizagem e desenvolvimento das novas gerações e a Psicologia ao estudar mais detidamente o que acontece com o indivíduo e a pessoa. ${ }^{1}$

No Brasil este processo também passou por uma série de etapas na implantação das idéias psicológicas no país. O modelo de Educação da época era repressor. A idéia era que a criança deveria ser modelada até se tornar o mais próxima possível dos adultos. A especificidade da criança ficava perdida em propostas que visavam domar as chamadas tendências inatas. Alguns representantes destas concepções foram Alexandre de Gusmão e Manuel de Andrade Figueiredo. Azeredo Coutinho defendia a idéia de que o controle externo deveria ser interiorizado pela criança. O que acabou gerando uma proposta educativa onde prêmios e castigos eram continuamente manipulados, instaurando uma idéia de que para bem educar, era necessário ter mão de ferro, principalmente em relação

\footnotetext{
${ }^{1} \mathrm{O}$ conceito de indivíduo pode ser localizado como uma das discussões mais importantes do ponto de vista da implantação da noção de subjetividade na história da cultura. Implica em perceber o ser como podendo conformar-se de uma maneira mais singular, única. O conceito de pessoa, por sua vez, apresenta traços mais direcionados para uma vertente social. $\mathrm{O}$ indivíduo interagindo socialmente, o indivíduo adquirindo uma persona.
} 


\section{DOSSIÊ \\ Área Temática: Ensino de Psicologia "Diálogos sobre a Docência em Psicologia"}

aos filhos dos gentios, porque acreditava-se que estes apresentavam problemas genéticos e sociais.

Qual era o papel da Psicologia na Educação naquela época? Ela era vista como um simples instrumento para que esta última pudesse se consolidar melhor. A Psicologia não apresentava especificidade.

\section{A PSICOLOGIA E O SÉCULO XIX}

Com a instauração do ensino superior no Brasil surgiram algumas mudanças na maneira de se considerar a relação entre a Psicologia e a Educação. O ensino passou a ser pensado em um outro contexto. Foi possível se estabelecer uma reflexão maior. O surgimento das faculdades - com os seus diferentes cursos e práticas - acabou instaurando uma nova forma de lidar com o trabalho de cada área. Um exemplo significativo foi o da implantação das faculdades de Medicina da Bahia e do Rio de Janeiro. Fundadas em 1808 como cadeiras já, a partir de 1910, passaram à condição de cursos.

É o momento em que a Medicina encontra as propostas higienistas. A idéia de que era preciso fazer a prevenção de doenças, a prevenção dos comportamentos utilizando os recursos educacionais da época. Com isso a escola tornou-se o grande alvo das propostas higienistas dos médicos sanitaristas. Eles propunham um saneamento físico e mental da sociedade. A escola adquiriu um lugar de destaque a partir de intervenções direcionadas a uma prática profilática. A formação moral das crianças e adolescentes torna-se assim o grande desafio para os sanitaristas e educadores.

A idéia básica era a necessidade de normalizar as condutas e os hábitos dos educandos pela repressão dos comportamentos considerados nocivos.

Surgem as chamadas escolas normais que irão se preocupar com a formação de professores. Eram cursos com a duração de dois anos.

Pode-se dizer que, neste momento, de uma maneira mais específica do ensino de Psicologia surge na história da Educação brasileira vinculado à Reforma Benjamin Constant, em 1890. Foi quando a disciplina Filosofia foi substituída pela disciplina 


\section{DOSSIÊ \\ Área Temática: Ensino de Psicologia "Diálogos sobre a Docência em Psicologia"}

Psicologia e Lógica. O que, posteriormente, possibilitou o estabelecimento de uma disciplina específica chamada Pedagogia e Psicologia.

Já em 1892, um projeto de lei de autoria de Paulo Egídio, propôs que a referida disciplina (Pedagogia e Psicologia) passasse a integrar o currículo das Escolas Normais. Sem falar que, nas demais disciplinas de Filosofia, também eram debatidos outros autores da Filosofia que tivessem um contato mais próximo com as discussões educativas. Por exemplo, eram utilizados na época os seguintes filósofos: Locke, Rousseau, Pestalozzi, Herbat e Spencer.

Alguns dos temas comumente encontrados nos programas da disciplina de Pedagogia e Psicologia: a inteligência, as sensações e a vontade, os processos envolvidos na aprendizagem, as recompensas e punições, etc. Ou seja, pode-se constatar que permaneciam temas do período anterior mais direcionado para um modelo repressivo acrescido de algumas propostas mais voltadas para uma investigação a respeito do que seria o processo de aprendizagem de alunos e professores.

A preocupação com o ensino elementar tornou-se, então, fundamental. Como

ensinar as crianças das mais diversas classes e contextos sociais? Gradativamente a Psicologia passa a ser voltar para uma discussão mais ampla a respeito desta novas questões.

\section{A PSICOLOGIA E A PRIMEIRA METADE DO SÉCULO XX}

É o momento em que surge uma preocupação com o novo século que se iniciava. Uma nova nação e um novo tempo. O ideário escolanovista passa a influenciar as ações. Surgem os primeiros profissionais interessados em criar entidades para discutir o que estava acontecendo com a Educação no Brasil. Muitos deles eram médicos sanitaristas e psiquiatras. A entidade de maior prestígio, na época, foi a Associação Brasileira de Educação.

O país começa a sofrer várias reformas educacionais a partir da década de 20. A Psicologia passa a ser vista como aquela que poderia dar um sustentáculo maior para a Educação, para o professor, para o aluno. 


\section{DOSSIÊ \\ Área Temática: Ensino de Psicologia "Diálogos sobre a Docência em Psicologia"}

O psiquismo era visto como um dos eixos fundamentais do processo. Surgem as preocupações com os aspectos conscientes e inconscientes do processo de aprendizagem.

O indivíduo é visto em um contexto mais direcionado para a singularidade. A pessoa trazendo os traços de seus contatos com os grupos sociais. A idéia de uma construção da personalidade, do indivíduo toma forma.

As relações sociais e a linguagem passam a ocupar um lugar de destaque no processo de formação do professor. O que importa, cada vez mais, é como a criança tece a linguagem e o pensamento, como ela interage socialmente.

As reformas educacionais se pautavam pelos princípios da Escola Nova tendo a Psicologia como o grande eixo estruturador do processo de construção do conhecimento da criança. A Psicanálise também ocupa um lugar de destaque em função das discussões relativas ao inconsciente, ao recalque e a estruturação do aparelho psíquico.

Foi o momento em que os professores e especialistas se interessam cada vez mais pelos estudos a respeito dos processos de construção da linguagem, da aprendizagem e do desenvolvimento da criança.

Surge uma preocupação com os circuitos patológicos. A deficiência mental passa a ser uma preocupação maior. No Brasil, Helena Antipoff se dedica a um estudo detalhado da maneira como ela se constitui.

A partir da década de 30 do século passado a Psicologia se consolida como uma área autônoma do saber. A Educação mantém com ela um intercâmbio intenso.

Surge a publicação de livros e teses de autores brasileiros e estrangeiros direcionados para estes temas. Aparecem revistas científicas de divulgação como a Revista Brasileira de Estudos Pedagógicos, a Revista de Psicologa Normal e Patológica, etc.

Em 1930 é fundada a Universidade de São Paulo, o que ampliará ainda mais o escopo da discussão relativa a importância da Psicologia em seu vínculo com os processos educativos.

Em 1940 é fundado o Sedes Sapienteae trazendo uma proposta de formação de psicólogos.

Em 1942 é fundada a Pontifícia Universidade Católica de São Paulo. 


\section{DOSSIÊ \\ Área Temática: Ensino de Psicologia "Diálogos sobre a Docência em Psicologia"}

A Psicologia ganha em espaço, campo e reconhecimento. Ela sai de um lugar secundário para ocupar um espaço cada vez mais prioritário nas discussões relativas aos processos educativos.

\section{A PSICOLOGIA E A SEGUNDA METADE DO SÉCULO XX: AS BASES PARA UM NOVO MILÊNIO}

Em 1962, a Lei 4119, de 27 de Agosto reconheceu a profissão de psicólogo no país. Ela dispôs a respeito de seus cursos de formação, através de uma proposta de cursos mínimos. A partir daí a relação entre a Psicologia e a Educação foi se tornando cada vez mais rica e intricada.

Por volta da década de 70 do século passado é possível encontrar uma quantidade crescente de cursos de Psicologia. Paralelamente, passa-se a vivenciar uma hipertrofia da atuação da Psicologia nos cursos de Pedagogia. Os psicólogos e os próprios educadores começam a fazer a crítica da maneira como a Psicologia vinha sendo utilizada nos cursos de Pedagogia.

O que acabou levando a um amplo questionamento maior do papel da Psicologia em relação à forma como ela deveria ou não ser utilizada na Educação, nas escolas, nas salas de aula, etc.

\section{O MOMENTO ATUAL: NOVAS CONFIGURAÇÕES}

Na virada do novo século não se questiona mais a importância da Psicologia em sua articulação com a Educação. O que interessa atualmente é que se possa abrir um diálogo mais frutífero e rico entre elas. Que elas possam trocar idéias entre si. Neste sentido gostaria levantar alguns aspectos que tem chamado a atenção dos estudiosos e especialistas dentro da área de ensino de Psicologia e do ensino de Psicologia no Ensino Médio. 


\section{FORMAÇÃO DE PROFESSORES E AS POLÍTICAS PÚBLICAS EM LICENCIATURA EM PSICOLOGIA : ALGUMAS QUESTÕES}

O que tem acontecido com as Políticas Públicas em Licenciatura em Psicologia? De que maneira tem se dado a formação do Professor de Licenciatura em Psicologia e do Professor de Psicologia no Ensino Médio? O que tem ocorrido com a formação do Professor de Psicologia no Ensino Médio?

São várias as tendências no processo de formação pelas quais os professores de Psicologia das Licenciaturas e do Ensino Médio tem passado. LevantareI a seguir algumas das tendências gerais pelas quais os professores tem passado.

$1^{\circ}$ ) Na década de 70 do século passado - Sob influência da psicologia comportamental e da tecnologia educacional as políticas públicas privilegiaram a dimensão técnica do processo de formação de professores e especialistas. O professor era visto como um organizador dos componentes dos processos de aprendizagem que deveriam ser rigorosamente planejados para garantir os resultados instrucionais mais eficientes.

$2^{\circ}$ ) Na década de 80 do século passado - o debate a respeito do processo de formação se direcionou para a discussão de dois pontos básicos: o caráter prático da experiência pedagógica e o compromisso do educador com as classes populares.

$3^{\circ}$ ) Na década de 90 do século passado a formação do professor se voltou para a construção do professor pesquisador. O que possibilitou uma discriminação mais clara entre o saber escolar, o saber docente e a formação prática do professor.

$4^{\circ}$ ) A partir de 2000 a ênfase no processo de formação do professor tem recaído na constituição do professor-reflexivo. Do professor que consegue repensar a sua atuação em sala de aula.

\section{OS IMPASSES DO PROFESSOR DE PSICOLOGIA DA LICENCIATURA E DO PROFESSOR DE PSICOLOGIA DO ENSINO MÉDIO}

Um aspecto que é preciso assinalar é que desde a década de 90 do século passado que os professores de Psicologia do Ensino Médio não tem tido nenhum tipo de processo de capacitação ou atualização. O que acabou ocasionando problemas nas práticas atuais 


\section{DOSSIÊ \\ Área Temática: Ensino de Psicologia "Diálogos sobre a Docência em Psicologia"}

apresentadas pelos professores das licenciaturas e os professores de Psicologia do Ensino Médio.

Segundo relatos dos estagiários das disciplinas de Práticas de Ensino em Psicologia ou Metodologias do Ensino de Psicologia é bastante comum os professores de Psicologia não ter idéia do que ensinar quando eles ensinam Psicologia no Ensino Médio. Algo impensável, por exemplo, para um professor de Matemática no Ensino Médio ou um professor de Língua Portuguêsa que apresentam programas bastante delineados.

Assinalarei, a seguir, algumas das principais dificuldades observadas pelos alunos da disciplina Metododologia do Ensino de Psicologia I e II na Licenciatura em Psicologia da Faculdade de Educação da Universidade de São Paulo, no período de 1995 a 2007.

1. Falta um conteúdo programático claro a respeito do que o professor da disciplina Psicologia do Ensino Médio pode ensinar. Uma decorrência do conteúdo da disciplina Prática de Ensino de Psicologia e Metodologia do Ensino de Psicologia que também não delineiam para o aluno o que ele pode ensinar.

2.Há uma enorme confusão entre o professor de Psicologia e o psicólogo escolar.

3.Muitos professores por não saberem o que ensinar acabam saindo da área de ensino e se direcionando para as práticas alternativas de Orientação Vocacional, Orientação Sexual. 4.Muitos professores não tem idéia do que é o ensino de Psicologia. Eles se propõe a trabalhar com as teorias psicológicas de uma forma geral sem lidar com elas em seu ângulo mais específico relativo ao ensino.

5.A maior parte não tem idéia de como ensinar a Psicologia em sua vertente científica o que acaba fazendo com que muitos professores de Psicologia no Ensino Médio tragam conteúdos de psicologia de senso comum. Por exemplo, artigos de revista de larga divulgação são trabalhados como se trouxessem os verdadeiros conteúdos científicos da Psicologia. O que acaba banalizando o ensino de Psicologia e a própria Psicologia enquanto área de conhecimento.

6.Os professores de ensino superior também não tem uma idéia clara do que é o ensino de Psicologia na Licenciatura em Psicologia. O que faz com que os programas apresentem um leque bastante amplo de possibilidades do que poderia ser ensinado que vão desde discussões relativas à Didática até questões curriculares extensas.

(C) ETD - Educação Temática Digital, Campinas, v.8, n.2, p.225-235, jun. 2007 - ISSN:1676-2592 


\section{DOSSIÊ \\ Área Temática: Ensino de Psicologia "Diálogos sobre a Docência em Psicologia"}

\section{O ENSINO DE PSICOLOGIA: UMA ATIVIDADE MAIOR OU MENOR?}

Muitos psicólogos continuam acreditando que o o ensino de Psicologia seja uma atividade menor. Que a atuação por excelência do psicólogo deveria ser relativa à clínica, à psicologia social, à psicologia crítica, etc.

Há uma crença que a Psicologia enquanto área de conhecimento - por si mesma já forneceria ao Professor condições plenas de exercer a sua atividade. Com isso o ensino é degradado. Ele se torna uma atividade menor que pode ser exercida por qualquer um sem nenhum tipo de preparo. Outros ainda sobrevalorizam o ensino acreditando que seja possível dominá-lo, controlá-lo.

Contudo, o que os educadores e pesquisadores tem discutido mais recentemente revela que o ensino não se encontra nem de um lado e nem de outro. Ele não é algo aprendido naturalmente. Hoje faz-se a crítica de um modelo de vocação trazido ao longo de séculos passados.

O ensino na sociedade contemporânea é visto como um processo denso que exige um trabalho de construção.

Para Philipe Meirieu a experiência pedagógica é, fundamentalmente, uma experiência de resistência ao outro, ao projeto de ensino que eu desenvolvo sobre ele. Com isso quero dizer que o ensino não pode ser reduzido a um simples processo de transmissão de conteúdo. Ele diz respeito também a forma como o aluno recebe o conteúdo, como lida com ele.

Por isso, é fundamental pensarmos no ensino de Psicologia como um trabalho que exige uma interlocução constante com o aluno. Um trabalho de construção conjunta. O que faz com que a atuação pedagógica não seja um ato apenas do professor. Ela é uma construção que se dá entre alunos e professores. Ela está em um lugar intermediário. O que faz com que possamos dizer, como Philipe Meirieu, que a Pedagogia esta sempre entre o dizer e o fazer. Ela está entre o aluno e o professor. 


\section{DOSSIÊ \\ Área Temática: Ensino de Psicologia "Diálogos sobre a Docência em Psicologia"}

\section{CONCLUSÃO}

Fazer uma reflexão mais profunda a respeito do que seja ensinar Psicologia tornase absolutamente essencial nos dias de hoje. Uma discussão que implica discutir o que é educar dentro do contexto atual de uma sociedade globalizada, de uma sociedade da informação.

Para isso é necessário que se amplie o fóco redutor como que ela tem sido trabalhada. Uma discussão que resgate tanto a importância do ensino quanto a importância da própria Psicologia e Educação dentro dos contextos educativos contemporâneos.

Há múltiplas formas de se lidar com a Educação e a Psicologia. Resta agora saber como e de que maneira isso tem sido feito para que o ensino de Psicologia na Licenciatura e no Ensino Médio redunde em prol dos alunos. Para que ele não se perca em relação à maneira como nós temos estabelecido as nossas práticas redutoras.

Ensinar Psicologia e Psicologia no Ensino Médio exige um olhar outro. Um olhar onde a prática pedagógica esteja cada vez mais próxima dos alunos. Uma prática que seja crítica que possibilite aos alunos se posicionarem em um mundo cada vez mais confuso e desbussolado. Em um mundo onde a transmissão das informações através das mídias eletrônicas é contínua. O que não quer dizer que ela possibilite a construção do saber dos alunos.

A Psicologia no Ensino Médio poderia ser o lugar que possibilitasse uma localização melhor do aluno frente à sua cultura, a Educação, à escola e à sua vida. Para isso torna-se necessário que o professor tenha mais claro a sua forma de atuação neste processo. Algo a ser trabalhado, algo a ser construído. 


\section{DOSSIÊ \\ Área Temática: Ensino de Psicologia "Diálogos sobre a Docência em Psicologia"}

\section{REFERÊNCIAS}

AZZI, R.G.; SADALLA, A. M. F. A. (Org.). Psicologia e formação focente: desafios e conversas. São Paulo: Casa do Psicólogo, 2002.

AZZI, R. G.; BATISTA, S. H. S. S.; SADALLA, A. M. F. A. Formação de professores: discutindo o ensino de psicologia. Campinas: Alínea, 2001.

LAROCCA, P. Psicologia na formação docente. Campinas: Alínea, 1999.

MRECH, L. M. Casa de ferreiro, espeto de pau: o campo da psicologia no ensino médio. Campinas: Papirus, 2001.

OLIVEIRA, M. K.; TRENTO, D.; REGO, T. C. (Org.). Psicologia, educação e as temáticas da vida contemporânea. São Paulo: Moderna, 2002. 